\title{
Insights into Anticipation Capacity Development Programme at Interpersonal Interaction
}

\author{
Marina M. Solobutina ${ }^{1}$ \\ ${ }^{1}$ Kazan Federal University, Kazan, Russia \\ Correspondence: Marina M. Solobutina, Kazan Federal University, Kremlyovskaya Street 18, Kazan, 420008, \\ Russia.
}

Received: January 19, 2014

Accepted: February 22, 2015 Online Published: March 25, 2015

doi:10.5539/res.v7n5p137

URL: http://dx.doi.org/10.5539/res.v7n5p137

\begin{abstract}
The paper presents the experimental findings proving the need for the development of anticipatory competence of future non-science specialists as a component of their professional competence. The objective of the research is to improve the level of anticipatory skills of university students at verbal and cogitative and communicative levels via a developmental training programme. Anticipatory skills in a speech activity are considered as a factor of adequacy of communicative situations and effectiveness of interpersonal interaction. The results collected after comparing the features of speech anticipations before and after the training demonstrate how the development of predictive abilities at speech, cogitative and communicative levels contributes to a high level of situational adaptability in various communicative situations. The anticipatory competence training programme of future non-science specialists has proved its effectiveness. The qualitative assessment of changes in terms of anticipation at speech, cogitative and communicative levels has allowed toascertain the productivity of the proposed method.
\end{abstract}

Keywords: anticipation, probable prediction, professional competence, educational activities, university students

\section{Introduction}

\subsection{Actualizing the Problem}

The relevance of the research is justified by the currently discussed issues of training of non-science students, namely by the issues of formation of professional competence (Teasley, Archuleta, \& Miller, 2014). Professional competence proper is a system of professional pedagogical and subject knowledge and skills (Watson \& Fox, 2015). Organization of psychological and pedagogical conditions of the educational process for the development of professional competence (Garet et al., 2001; Torkunova et al., 2014; Rakhmanova et al., 2014; Ganieva et al., 2014; Vlasova et al., 2015) as a complex and multi-level system should be implemented when all of its components (educational, communicative, social, personal, anticipatory competences) are taken into consideration (Shen-Miller, Schwartz-Mette\& Sickle, 2014). Achievement of a high level of social (Judge, Bono, \& Ilies, 2002) and professional competence of non-science and pedagogical staff (Zhuravlev \& Sergienko, 2012) requires a high level of education (Hadar \& Brody, 2010), mastering the means of cognitive and practical activities, situational adaptability in many different communicative situations, a high level of proficiency and the ability to anticipating the course of events that determine adaptive behaviour (Hardré, Ling, Shehab, \& Herron, 2014).

\subsection{Explore Importance of the Problem}

In modern science researchers are attracted by a person's anticipation as an ability to act and take certain decisions with a specific time and spatial anticipation regarding the anticipated future events. To date, there has been carried out profound research of neurophysiological, psychophysiological foundations of anticipation (Nichiporenko \& Mendelevich, 2006), the role of anticipation in providing cognitive processes, special aspects of probabilistic forecasting in health and disease (Abitov, 2013; Akhmetzyanova, 2014), the development of anticipation in early ontogeny (Sergienko, 1997), anticipation in selected activities.

There exist various models of development of educational (Masalimova et al., 2014; Ivanov et al., 2015; Kovaleva et al., 2015; Shaidullina et al., 2014, 2015), social (Brand \& Moore, 2011) and communicative competences (Edmunds \& Richardson, 2009), but it is also fair to say, little attention was paid to the 
development of anticipatory (prognostic) skills (Cheraneva, 2013). Accordingly, the scientific and practical interest lies in the development and implementation of the programme aimed at the building of anticipatory consistency as a component of social and professional competence of future professionals.

Nevertheless, the issue of the development of predictive abilities in a variety of activities and social institutions has not been researched fully at the current stage of the development of science. There still remain unresolved features of anticipation on the communicative level. Anticipation in interpersonal interaction has been little studied both theoretically and experimentally, although the importance of the issue is clearly recognized. Research of anticipatory skills, as well as the works the subject study of which were the elements of social competence, admit a significant role of anticipation in the situation of interaction between the subject and the subject.

\subsection{Definition of Anticipation}

Anticipatory skills begin to form since birth under the influence of natural instincts and training, but the highest levels of anticipation (speech, cogitative and communicative) develop only in early adolescence (Sergienko, 1997). Qualitative improvement of thinking in adolescence as a mediated and generalized reflection of reality involves the establishment of cause-and-effect relationships in the long term, consideration of the probabilistic nature of the future, the conclusiveness of the forecast. Anticipation allows the formation of goal-setting and formation of time perspective of the subject of the activity. Shaping a world-view affect the motivation of the individual in their youth (Kalatzkaya, Kostyunina, \& Drozdikova-Zaripova, 2014) when the leading motives are connected with life plans, and self-determination requires the development of correct value judgments in respect of others and appropriate assessment of expectations from others (Lisitzinaet al., 2014; Ganieva et al., 2015).

Adolescence is a time of professional self-determination of the individual. Accordingly, an essential condition for the development of anticipatory skills at the highest levels is vocational training and professional activities. Developing the ability to predict in a targeted training is much more intense rather than spontaneous.

\subsection{Status of a Problem}

In her study Regush (2003) writes that in the process of training in pedagogical colleges improvement of skills to predict should take place by the end of training. First-year students normally lack connection between the indices of the same quality of thinking. Graduate students can display relative independence of the thought processes from the type of predictive asks. During the training the development of thought processes create an opportunity for the formation of the ability to predict events through the mastery of professional expertise.

In the course of vocational training anticipation enables goal setting, goal formation and forming of a time perspective of the subject of activity. Obviously, anticipation processes play a significant role in professional activities. If the issue of anticipatory activity of a specialist has been little studied, the issue of anticipation of pupils in domestic and foreign psychology remains unfinished. The analysis of research in this area has shown that, in general, the authors proposed various models of social and communicative competence (Shishova, 2014; Epstein \& Hundert, 2002), paying little attention to the development anticipatory (prognostic) abilities.

Accordingly, the scientific and practical interest lies in the development and implementation of programmes for the development of anticipatory skills as a component of professional competence of future specialists. Based on the above mentioned contradiction, there has been formulated a scientific challenge of how to enhance academic students' anticipatory skills at verbal, cogitative and communicative levels by means of a developing training programme.

\section{Methodology of the Research}

\subsection{The Tasks of the Research}

The following goals were set to achieve the objective:

- To develop and test a program of the development of probabilistic prediction in a group of first-year university students;

- To study university students' anticipatory abilities on a communicative level (personal and situational anticipatory consistency) before and after the developmental programme;

- To determine the nature of time perception and chronometric features of university students before and after the developmental programme;

- To assess the level of development of university students' verbal and cogitative processes (flexibility and critical thinking, productivity and capacity of associative processes) before and after the developmental 
programme;

- To identify significant differences in the level of development of the verbal, cogitative and communicative anticipatory abilities of the university students participating in the anticipation developmental programme and the students in the control group.

\subsection{Methodology and Empirical Methods}

When studying anticipation, of great significance were the general psychological patterns of the mechanisms revealed by such Russian psychologists as Lomov and Surkov (1980), Mendelevich (2006), Sergienko (1997). When considering anticipation in verbal activity of particular importance was R. Frumkina's concept, according to whom in speech mechanisms there is a hierarchical organization of the elements of speech, corresponding to the frequency of their occurrence in a person's speech activity. There were also taken into account the main doctrine provisions on the impact of the awareness of general idea of an utterance on speech prediction. An important position in the study of speech anticipation features in semantic perception of linguistic resources is the notion of a two-level prediction (semantic and verbal hypotheses levels) that are thoroughly described in the works of Zimnyaya (2001). A significant component of the theoretical framework of the study was the doctrine by Regush (2003) on the structure of the ability to predict in the learning process at a university and during actual teaching.

As diagnostic tools of anticipation on verbal and cogitative level there was used a method of obtaining subjective frequency assessment of words, a method of restoration of "noisy" words, a method of gap filling, and a direct association test. To diagnose prognostic communicative abilities there was used a test on anticipatory consistency (Mendelevich, 2006). To study the viability and flexibility of thinking there was chosen a method of an "Open Envelope". To study the temporal orientation of the person there was used a "Time perception" method. The level of anticipation ability was examined by the test of Regush (2003). The following statistical methods for data processing were used: descriptive statistics, $t$-Student's criterion).

\subsection{Survey Sample}

The group of the subjects was made up of the first and second year students of the Institute of Pedagogy and Psychology of Kazan Federal University. The group of 100 people was divided equally into the experimental and control groups. The experimental group consisted of the students who participated in the training "Development of anticipatory abilities" after the first stage of the test. Upon completion of developmental activities there was carried out a repeated diagnostics. The study was based on the formative assessment.

\section{Training Description}

The proposed training programme on anticipatory consistency of soon-to-be non-science specialists was designed in such a way as to create conditions for the development of prognostic abilities on verbal, cogitative and communicative levels of anticipation.

Training objective: to provide an opportunity for the subjects to evaluate the level of ability to predict and develop anticipatory abilities and an opportunity to display them in different situations.

The main objectives (targets) of the training:

- Situational adaptability and fluency in verbal and non-verbal means of behaviour;

- The ability to quickly and adequately deal with numerous and diverse communication situations;

- Mastery of effective communication techniques;

- High level of proficiency;

- Responsiveness of verbal and cogitative processes;

- Adequate probabilistic structure of internal lexicon;

- The ability to predict verbal behaviour in order to select appropriate lexical units.

The training included the exercises aimed at the development of the ability to predict people's behaviour, turns of everyday life situations, planning of life prospects, forecasting of professional situations, as well as exercises on associative and flexible thinking.

\section{Results}

While studying the students' anticipatory consistency on a communicative level there were obtained certain results. As a result of corrective measures the proportion of the subjects who demonstrated a normative type of probabilistic forecasting increased significantly $(\mathrm{p} \leq 0.05)$. Predicting life events and situations, spatial and time 
anticipation became adequate. The students noted that after the experimental exposure they purposefully excluded the single-version prediction.

In assessing the level of anticipatory abilities development it was revealed that the training contributed to the development of anticipatory abilities, since the data obtained from the experimental group increased significantly $(\mathrm{p} \leq 0.01)$. Comparing the results of the test in the experimental group before and after the training, the following trends can be noted. Prior to the developmental activities the subjects mainly gave a one-sided analysis of the situation and thought over only one outcome. This result indicated a mono-variant prediction accompanied by criticality and rigidity of thinking. Inability to give diversified prediction of the future and reactions to their own behaviour can lead to inefficient interaction with other people and reduces productivity of activities.

After the training, the subjects mainly chose a comprehensive analysis of the situation with different variants of the outcome of events, as well as the most appropriate action was considered prediction of the situation and the analysis of the situation first, and then move to specific actions in order to achieve a given goal. The developmental activities helped form a norm-variant type of forecasting with a sufficient set of outcome. Changing the type of prediction allowed the students to adequately comprehend the reality and adapt to it.

The study of temporal decentration (time perception) and chronometric features of university students showed that in all three groups the majority of the subjects are highly focused on the present. Also, there are quite high figures demonstrating the students' orientation toward the future, or both toward the present and the future. This may indicate a students' desire not only to know the present but to build short and long life plans. Decentration into the future is linked with responsibility, prediction of the consequences of decisions taken and assessment of their capabilities in their implementation. Determination, as a trait of character reflecting the unity of will and intellect, is characteristic of people oriented to the future.

The study of the student's anticipatory abilities on a verbal and cogitative level was carried out in two ways: when predicting individual lexical units and using verbal communications. The level of development of the students' mental operations in the second part of the experiment increased. As a result of the training, the students demonstrated a higher degree of flexibility of thinking and a greater variability in solving problems. The average level of productivity of mental operations was demonstrated only by $18 \%$ of the subjects, and a high level was typical for $82 \%$ respectively.

According to the analysis of the average results obtained by the $t$-criterion, significant differences were detected in the experimental group before and after the training ( $\leq \leq 0.05$ ). These differences indicate that the subjects learned to predict their actions to achieve accurate results. Also, this result confirms an increase in the efficiency of task completion and indicates a high level of flexibility and forward-thinking in a group of students that attended classes on the development of anticipation on verbal, cogitative and communicative levels.

To determine the efficiency of associations the subjects did a Direct Association Test. In all three groups, the number of central reactions always reached the standard value thus indicating language fluency and a sufficient level of verbal development of the subjects. Prior to the developmental activities, according to the grammatical criterion, the first-year students mainly demonstrated a syntagmatic type of response, namely the complexity of thinking. According to the paradigmatic type of verbal and cogitative processes there were revealed significant differences between the students in the control group and the students attending classes on anticipation development $(\mathrm{p} \leq 0.01)$. Consequently, the anticipation ability developmental program on verbal, cogitative and communicative levels actually enhances productivity of verbal and cogitative processes.

Table 1. Analysis of the programme effectiveness

\begin{tabular}{|c|c|c|c|}
\hline \multirow[b]{2}{*}{ Indicators } & \multicolumn{3}{|c|}{ Compared groups (tempirical) } \\
\hline & $\begin{array}{l}\text { The experimental group } \\
\text { before and after }\end{array}$ & $\begin{array}{l}\text { The control group and } \\
\text { the experimental group } \\
\text { after }\end{array}$ & $\begin{array}{l}\text { The control group and } \\
\text { the experimental group } \\
\text { before }\end{array}$ \\
\hline General anticipatory consistency & 1.3 & 1.5 & 0.8 \\
\hline Personal anticipatory consistency & 1 & 1.4 & 0.8 \\
\hline Time anticipatory consistency & 0.3 & 0.1 & 0.3 \\
\hline $\begin{array}{l}\text { Movement } \\
\text { consistency }\end{array}$ & $1.8^{*}$ & 1.2 & 0.2 \\
\hline
\end{tabular}




\begin{tabular}{llll}
\hline Level of anticipatory abilities & $\mathbf{2}^{*}$ & $\mathbf{2 . 1 *}$ & 1.2 \\
Time orientation to the present & 0.1 & 0.5 & 0.6 \\
Time orientation to the future & 0.3 & 0 & 0.2 \\
Time orientation to the past & 0.5 & 0.4 & 0.8 \\
$\begin{array}{l}\text { Flexible thinking } \\
\text { Associative thinking (logical) }\end{array}$ & $\mathbf{2 . 3 * *}$ & $\mathbf{1 . 9 *}$ & 0.3 \\
$\begin{array}{l}\text { Associative thinking } \\
\text { (paradigmatic) }\end{array}$ & $\mathbf{3}^{* * *}$ & $\mathbf{2 . 1 *}$ & 1.4 \\
$\begin{array}{l}\text { Paradoxical coefficient } P \\
\text { Standard coefficient } S\end{array}$ & $\mathbf{4 . 0 3}^{* * *}$ & $\mathbf{1 . 8}^{*}$ & 0.6 \\
$\begin{array}{l}\text { Adequate speech prediction } \\
\text { coefficient } B\end{array}$ & 1.1 & $\mathbf{8}^{* * *}$ & 1.3 \\
\hline
\end{tabular}

To study the students' probabilistic organization of idiolexicona method for obtaining a subjective frequency words was used. The experiment involves presenting students a set of stimulus words (40 nouns in Russian) in order to scalethem in accordance with the subjective perception of their frequencies. The stimulus words were selected in such a way that the list contained high-frequency (20) and a low-frequency words (20), as well as non-existent "anchor" words (6). Paradoxical coefficient $P$ was used as a number convenient for the description of the degree of difference of points of one student from the points of a group of the subjects. There was made a "turning" table which is the result of a simple transformation of matrix of distribution of points $\bar{X} i j$. Instead of the $\bar{X} i j$ points there was used $100-\bar{X} i j$. Each word was indicated by a point distribution, median, mode of distribution, minimum and maximum of penalty points. Deviation of a student's points from the mode of distribution of a group's points was calculated as "penalty points". An individual point of the frequency of a word which coincided with the mode referred to zero penalty. To describe a subject's general performance the paradoxical coefficient $P$ was calculated according to the formula: $P_{I=} \frac{\sum_{i}}{\sum_{\min }}$, with $\sum_{i}$-the amount of collected "fines" by a certain student, and $\sum_{\min } \longrightarrow$ a minimum possible amount of fines in a group. The more a student's points coincide with the mode the closer the value of $P$ to 1 .

To study the peculiarities of construction of a subjective verbal prediction of the subjects a method of noisy words was used. The subjects were given a set of words in which some letters were replaced by dashes. The task of the subjects was to reconstruct the "noisy" words. For each stimulus word there was known in advance the whole set of possible fillers with the word-fillers obviously differing in frequency of occurrence in speech. The subjects were required to give only one answer. There was no time limit. The subjects' activity was assessed depending on what words were selected as answers-more or less frequent ones. It was assumed that in the case of normally occurring prediction processes the subject had to give as an answer to each stimulus a more frequent word out of several possible fillings, and in case of abnormal actions - a less frequent one.

The set of stimuli consisted of 10 models (an Infinitive) with 6-7 optional fillings for each one. The result of the experiment was distribution of median points of frequency word-fillers with the score points $(+2,+1,0,-1,-2)$ corresponding to the five intervals which contained their medians. The subjects' activity is described by $B$ 
coefficient which varies from 0 to 1 and is calculated by the formula: $\quad B=1-\frac{\sum_{\max -} \sum_{i}}{\sum_{\max -} \sum_{\min }}$, with $\sum_{i}$ -the sum of points scored by a certain subject; $\sum_{\max }$ - highest possible score; $\sum_{\text {min }}-$ minimum possible score. $\mathrm{B}=1$ represents the best possible performance when the total score of the subject is equal to the maximum possible sum of points.

The results of the experimental group improved significantly after the developmental programme. This is confirmed by both the individual data and the $t$-test data. Significant differences were detected in the experimental group before and after the training $(r \leq 0.01)$ as well as in the control and experimental group after the training $(r \leq 0.01)$. The qualitative analysis of the responses of the subjects allowed to explain the content of the identified changes in the structure of the internal lexicon. It should be noted that if before the training many of the words were characterized by a large scale of individual points, then after the training the responses became clearer and more specific. In general, in all the three groups the subjects, firstly, identified correctly which type (frequent or rare words) a specific stimulus referred to, and, secondly, indicated the degree of difference between the stimuli within the same type. Thus, we can conclude that anticipatory abilities in verbal activity when updating certain lexical units in the subjects of all the three groups are at a sufficient level of development, but after taking part in special developmental programmes anticipatory abilities tend to improve at a verbal level.

In our research the study of anticipation at the semantic perception of speech was based on Ebbinghaus's method which consists of two texts with gaps for phrases in every sentence. The subject was asked to fill in the gaps to complete a story. The following factors were used when processing the results: the total number of response options used in each group of the subjects; the speed of word selection; the adequacy of the choice of lexical units; the probabilistic nature of the selected lexical units (frequency distribution for each gap); difficulties in finding the required words; the pattern of gap filling: aspiration of the subject to match occurring semantic hypothesis with the contents of the text, aspiration to maintain a meaningful connection of the sentences.

To measure the quantitative behaviour of the subject while doing the task there was selected the $\mathrm{S}$ "commonalty ratio" that reveals the relation of the degree of the studied trait in a particular subject to the maximum possible degree of this trait. The S ratio was calculated by the formula: $S_{i}=\frac{\sum_{i}}{\sum_{\text {mac }}}$, with $\sum_{i}$-the sum of responses of a particular subject the frequency of which in a healthy group is more than the average; $\sum_{\text {maz }}$-the total number of a subject's responses (it is constant in the current method). The $\mathrm{S}$ ratio changed from 0 to $1 ; \mathrm{S}=1$ corresponded to the best possible behaviour when the subject filled all the gaps with high frequency options.

The distribution of the values of the $\mathrm{S}$ ratio, which described the features of semantic hypothesising, differed considerably in the control and experimental groups after the training $(\mathrm{p} \leq 0.01)$. Having compared the individual data and the values of the $t$-test, we can conclude that anticipation on the level of actualization of individual lexical units $(\Pi)$ among the subjects of the experimental group is on a fairly high level, and as for the anticipation in semantic verbal perception the students had difficulty filling gaps. The experimental group after the experimental impact displayed a tendency to reduce the time spent on the text, on the accuracy of the given options, as well as on the increase of high frequency responses.

\section{Discussion}

It has been found out that the initial stage of studying at a higher educational institution is characterized by student-situational anticipatory inconsistency. When conducting additional developmental activities there is a tendency to increase the level of anticipatory abilities of students on a communicative level. There are significant differences in the level of development of anticipatory abilities of students participating in the probabilistic forecasting developmental programme and of the subjects in the control group.

The findings assert that the students at the initial stage of university training are mainly focused on the future when dealing with life's problems and organization life space. The results of the analysis of time perception after 
the developmental activities showed that the students experienced qualitative changes in the perception of time that is linked with the reorientation to the present life.

It has also been revealed that the undergraduate students possess an average level of flexibility and critical thinking. Unproductive and spasmodic verbal and cogitative processes are typical for the majority of the subjects which speaks for some infantilism of thinking. By the end of the programme on the development of anticipation on verbal, cogitative and communicative levels there was marked an increase in the productivity of verbal and cogitative processes among the students.

It has been determined that the actualization of certain lexical units by university students at the beginning of training is on sufficient level, the process speech anticipation is characterized by adequacy, namely with a lack of information in a speech situation high or medium frequency words are selected being generated better and faster than the low frequency ones. With regards to the functioning of anticipatory mechanisms in semantic speech perception and actualization of verbal communication, it can be concluded that the subjects of both experimental and control groups had some difficulties - trouble in the process of meaning-making and improper use of Russian lexical units. After the training, it was possible to trace a tendency of increase in the effectiveness of anticipation on the level of semantic hypotheses with an increase in number of high frequency and adequate verbal communication.

Thus, the empirical evidence suggests that the testing of the programme of development of anticipatory abilities of university students on verbal, cogitative and communicative levels was successful; experimentally there was proved the effectiveness of the proposed developmental exercises. Taking into account that adolescence is the most sensitive period for the development of anticipation on the highest levels, inclusion of anticipatory training in the educational process of higher educational establishments is regarded as appropriate.

\section{Conclusion}

The results of comparison of the features of verbal anticipation before and after the anticipatory training demonstrate how the development of predictive abilities on verbal, cogitative and communicative levels contributes to a high level of situational adaptability in many different communicative situations. In addition, taking into account the flexibility and integration of core professional competencies, the development of anticipatory abilities is carried out not in isolation but largely determines the high level of education, cognitive and practical activities.

The research has proved the necessity of developing of anticipatory abilities of university students on verbal, cogitative and communicative levels. The training program of future non-science specialists has proved its effectiveness. The qualitative assessment of changes in the ratio of anticipation on verbal and communicative levels allowed to ascertain the productivity of the proposed method.

There has been proved the necessity of consideration and development of anticipatory (prognostic) consistency in the implementation of psycho-pedagogical conditions of formation of professional competence of non-science students and student-teachers in the framework of the educational process of a higher educational institution. One of the aspects of improving the quality of training of future non-science specialists may be the introduction of the theory and practice of prognostication into the academic programme. The task of developing a programme aimed at the development of anticipatory competence and development of anticipatory abilities in speech contains a new evidence-based approach to solving the tasks of psychological ecology and adaptation to the changing environmental conditions.

\section{Acknowledgments}

The work is performed according to the Russian Government Program of Competitive Growth of Kazan Federal University.

\section{References}

Abitov, I. R. (2013). Peculiarities of coping with stress by healthy persons and patients with psychosomatic and neurotic disorders. Psikhologicheskii Zhurnal, 34(1), 86-96.

Akhmetzyanova, A. I. (2014). The Development of Self-Care Skills of Children with Severe Mental Retardation in the Context of Lekoteka. World Applied Sciences Journal, 29(6), 724-727.

Brand, B. R., \& Moore, S. J. (2011). Enhancing teachers' application of inquiry-based strategies using a constructivist sociocultural professional development model. International Journal of Science Education, 33(7), 889-913. http://dx.doi.org/10.1080/09500691003739374

Cheraneva, E. K. (2013). Mental ability to social perceptive anticipation as factors of professional development 
in Higher Educational Institutions. Moscow.

Edmunds, R., \& Richardson, J. (2009). Conceptions of Learning, Approaches to Studying and Personal Development in UK Higher Education. British Journal of Educational Psychology, 79(2), 295-309. http://dx.doi.org/10.1348/000709908X368866

Epstein, R. M., \& Hundert, E. M. (2002). Defining and assessing professional competence. Jama-Journal of the American Medical Association, 287(2), 226-235. http://dx.doi.org/10.1001/jama.287.2.226

Ganieva, Y. N., Azitova, G. S., Chernova, Y. A., Yakovleva, I. G., Shaidullina, A. R., \& Sadovaya, V. V. (2014). Model of high school students' professional education. Life Science Journal, 11(8), 504.

Ganieva, Y. N., Sayfutdinova, G. B., Yunusova, A. B., Sadovaya, V. V., Schepkina, N. K., Scheka, N. Y., Gutman, E. V., \& Salakhova, V. B. (2015). Structure and content of higher professional school lecturer education competence.Review of European Studies, 7(4), 32. http://dx.doi.org/10.5539/res.v7n4p32

Garet, M. S., Porter, A. C., Desimone, L., Birman, B. F., \& Yoon, K. S. (2001). What makes professional development effective? Results from a national sample of teachers. American Educational Research Journal, 38(4), 915-945. http://dx.doi.org/10.3102/00028312038004915

Hadar, L., \& Brody, D. (2010). From isolation to symphonic harmony: Building a professional development community among teacher educators. Teaching and Teacher Education, 26(8), 1641-1651. http://dx.doi.org/10.1016/j.tate.2010.06.015

Hardré, P. L., Ling, C., Shehab, R. L., Herron, J., \& Nanny, M. A. (2014). Designing and evaluating a STEM teacher learning opportunity in the research university. Evaluation and Program Planning, 43, 73-82. http://dx.doi.org/10.1016/j.evalprogplan.2013.11.002

Ivanov, V. G., Shaidullina, A. R., Drovnikov, A. S., Yakovlev, S. A., \& Masalimova, A. R. (2015). Regional Experience of Students' Innovative and Entrepreneurial Competence Forming. Asian Social Science, 11(1), $35-40$.

Judge, T. A., Bono, J. E., \& Ilies, R. (2002). Personality and leadership: A qualitative and quantitative review. Journal of Applied Psychology, 87(4), 765-780. http://dx.doi.org/10.1037/0021-9010.87.4.765

Kalatzkaya, N. N., Kostyunina, N. J., \& Drozdikova-Zaripova, A. R. (2014). Motivational peculiarities of schoolteachers in Russia. Life Science Journal, 11(55), 243-247.

Kovaleva, N. I., Valeyeva N. Sh., Avilova N. L., Kharisova G. M., Khayrutdinov R. R., Khairullina E. R., \& Shaikhlislamov A. K. (2015). Recommended Practices for Improving the Competitiveness of the Russian Education Services Market under the Conditions of the International Educational Integration. Review of European Studies, 7(4), 1-5. http://dx.doi.org/10.5539/res.v7n4p1

Lisitzina, T. B., Pavlova, A. V., Khanmurzina, R. R., Vlasova, V. N., Chitalin, N. A., Maksimov, I. N., \& Zakirova, V. G. (2014). Features of the Professional and Motivating Training Content Design for Students Majoring in "Tourism". Asian Social Science, 11(1), 148. http://dx.doi.org/10.5539/ass.v11n1p148

Lomov, B. F., \& Surkov, E. N. (1980). Anticipation within activity. Moscow: Nauka.

Masalimova, A. R., Zakirova, V. G., Chernova, Y. A., Drovnikov, A. S., Shaidullina, A. R., \& Sakhieva, R. G. (2014). Structure and content of mentors psychological and pedagogical training curriculum. Life Science Journal, 11(7s), 381.

Nichiporenko, N. P., \& Mendelevich, V. D. (2006). Anticipation abilities phenomenon as a subject of psychological research. Psikhologicheskii Zhurnal, 27(5), 50-59.

Rakhmanova, A. R., Sadovaya, V. V., \& Denisova, M. Y. (2014). Socio-Cultural Potential of a scientific Library of Higher Education Institution in Students' value Attitude to Education Development. Asian Social Science, 11(1), 176. http://dx.doi.org/10.5539/ass.v11n1p176

Regush, L. A. (2003). Psychology of prediction: Success in foreknowledge. Saint Petersburg: Rech.

Sergienko, E. A. (1997). Anticipation as a principle of psyche development. Moscow: Science.

Shaidullina, A. R., Masalimova, A. R., Vlasova, V. K., Lisitzina, T. V., Korzhanova, A. A., \& Tzekhanovich, O. M. (2014). Education, science and Manufacture Integration Models features in Continuous Professional Education System. Life Science Journal, 11(8s), 478-485.

Shaidullina, A. R., Merzon, E. E., Zakirova, V. G., Mokeyeva, E. V., Karev, B. A., Burdukovskaya, E. A., \& Polevaya, N. M. (2015). The Peculiarities of Perspective Students Selection Mechanism by the Future 
Employers-Enterprise. Review of European Studies, 7(1), 68-73.

Shen-Miller, D. S., Schwartz-Mette, R., \& Sickle, K. S. V. (2014). Professional Competence Problems in Training: A Qualitative Investigation of Trainee Perspectives. Training and Education in Professional Psychology. http://dx.doi.org/10.1037/tep0000072

Shishova, E. O. (2014). Peculiarities of person's speech and thought activity in the context of multicultural education. Middle-East Journal of Scientific Research, 19(9), 1137-1141.

Teasley, M. L., Archuleta, A., \& Miller, Ch. (2014). Perceived Levels of Cultural Competence for School Social Workers: A Follow-Up Study. Journal of Social Work Education, 50(4), 694-711.

Torkunova, J. V., Khairullina E. R., Komelina V. A., Volkova N. V., \& Ponomarev K. N. (2014). The Peculiarities of Qualitative Information, Analytical Maintenance Innovative and Educational Activity Technological Projection in Higher Educational Institution. Life Science Journal, 11(8s), 498-503. Retrieved from http://www.lifesciencesite.com

Vlasova V. K., Kirilova G. I., \& Masalimova, A .R. (2015). Information and Logistic Foundations of Pedagogical Education Design and Content Education. Review of European Studies, 7(4), 54-58. http://dx.doi.org/10.5539/res.v7n4p54

Watson, C., \& Fox, A. (2015). Professional re-accreditation: Constructing educational policy for career-long teacher professional learning. Journal of Education Policy, 30(1), $132-144$. http://dx.doi.org/10.1080/02680939.2014.907446

Zhuravlev, A. L., \& Sergienko, E. A. (2012). Psychological problems of modern Russian society. Moscow: Institute of Psychology of Russian Science Academy.

Zimnyaya, I. A. (2001). Linguistic psychology of speech activity. Moscow: Rech.

\section{Copyrights}

Copyright for this article is retained by the author(s), with first publication rights granted to the journal. This is an open-access article distributed under the terms and conditions of the Creative Commons Attribution license (http://creativecommons.org/licenses/by/3.0/). 